\title{
Learning by Gamification: An Effective Active Learning Tool in Engineering Education
}

Patil Y. M.1* and Kumbhar P.D.2

1Assistant Professor, Department of Civil Engineering, Rajarambapu Institute of Technology, Rajaramnagar, Islampur - 415 414, District: Sangli (M.S), India

email: yashawant.patil@ ritindia.edu

2 Associate Professor, Department of Civil Engineering, Rajarambapu Institute of Technology, Rajaramnagar, Islampur - 415 414,District: Sangli (M.S), India

email: popat.kumbhar@ritindia.edu

*Corresponding author: Patil Y. M. (email): yashawant.patil@ ritindia.edu

\begin{abstract}
One of the latest buzzwords in engineering education is 'active learning' and 'Outcome Based Education'. Active learning refers to the idea that students are actively engaged in the learning process, rather than passively absorbing content. The COVID-19 pandemic has raised significant challenges for the higher education community worldwide. A particular challenge has been the urgent and unexpected request for previously face-to-face university courses to be taught online by using different online tools such as Microsoft Team, Zoom etc.
\end{abstract}

This paper describes the application of one of the gamification tools known as 'Kahoot' used for online teaching a course namely 'Irrigation and Hydraulic Structures' which is the core course of B.Tech. Civil Engineering Program. This course is related to the storage, transmission and use of water for irrigation purposes. Previously, the course was used to be taught by conventional methods in which the students were found to be unable to visualize various hydraulic structures such as dam, canal, cross drainage work etc. that are used for irrigation purposes and hence the expected course outcomes could not be attained. In the COVID-19 pandemic situation the same course was taught by online mode with the help of Microsoft Teams platform. However, it was difficult to engage all the 76 students and assess their performance. Hence, use of one of the gamification tools namely 'Kahoot' was done to assess and evaluate the performance of students. The entire class was divided into two groups namely 'Control Group', and 'Experimental Group'. The 'Control Group' was assessed using conventional teaching involving 'question answer session', while the 'Experimental Group' was assessed by using the 'Kahoot' tool of gamification. The results of the study shows that the performance of 'Experimental Group' in the Unit Test Examination (i.e. average marks) improved by over $18 \%$ compared to the performance of 'Control Group'. Thus, it can be concluded that use of 'gamification' as an active learning tool helps in enhancing the students understanding and hence attaining the expected outcomes. 
Keywords: Active Learning Tool, Irrigation and Hydraulic Structures (IHS), Outcome Based Education, Gamification

\subsection{Introduction}

Sometime in the second week of March 2020, state governments across the country began shutting down schools and colleges temporarily as a measure to control the spread of the COVID-19. It's been close to seven months and there is no certainty about when the school, college and universities will reopen. This is a crucial time for the engineering education sector as the final examinations of engineering and other disciplines, admissions, entrance tests of various universities and competitive examinations are all held during this period. As the days pass by with no immediate solution to stop the outbreak of COVID-19, school and university closures will not only have a short-term impact on the continuity of learning for more than 285 million young learners in India but also endanger farreaching economic and societal consequences.

The extensive school closures occurred during an era that has generally been shaped by rapid transformation in technological innovations and digitalization, not least in educational contexts. Online teaching provides instructors with greater flexibility to address varying learning styles and use different technologies. They can teach from the comfort of their own homes and do not need to be at a specific place at a specific time to teach or to interact with their students. In India, many higher educational institutes have used different online apps such as Microsoft team Zoom, Google Meet etc. During the online teaching learning process it becomes very difficult to engage all the students of the classroom using the active learning techniques such as 'Group Discussion', 'Think-Pair-Share' etc. which are commonly used in Outcomes Based Education system (OBE). There are several gamification tools available for online teaching which helps in enhancing the student's active involvement in the teaching learning process.

In the present study, the use of the 'Kahoot' tool was done in assessing the performance of students. Kahoot is an educational platform that is based on games and questions. Through this tool, teachers can create questionnaires, discussions, or surveys that complement academic lessons. The material is projected in the classroom and questions are answered by students while playing and learning at the same time. Kahoot promotes game-based learning, which increases student engagement and creates a 
dynamic, social, and fun educational environment. The Kahoot tool was used for online teaching and assessing the performance of final year B.Tech. Civil Students in the Unit Test Examination of the Semester VII course namely 'Irrigation and Hydraulic Structures (IHS)'. For assessment of students, the entire class was divided into two groups namely Control Group and Experimental Group for assessing their learning. The Control Group consisted of 26 students, while the Experimental Group consisted of 50 students. The 'Control Group' was assessed by using conventional techniques (question-answer, one minute paper etc.) whereas the Experimental Group' was assessed by adopting the Kahoot tool that involved mostly 'Multiple Choice Questions (MCQ)', and 'True-False' types questions. The performance of students was observed in the Unit Test Examination by comparing the marks obtained by the students of both groups. The results indicate that the performance of students' (i.e. average marks) is improved for the 'Experimental Group' of students by over $18 \%$ as compared to the 'Control Group' of students. Thus, from the present study it is concluded that gamification active learning tool is very useful for assessment of learning levels of students and also engaging them during teaching learning process that leads to students quality learning.

\subsection{Procedure of gamification Technique:}

The use of gamification tool namely 'Kahoot' was used to enhance the active involvement of the students and hence attain the expected learning outcomes. The expected course learning outcomes and of the course are as given below.

Course Outcomes: After successful completion of this course students will be able to

1. Analyze and design hydraulic structures

2. Compute storage capacity of various types of reservoir and their design aspects.

3. Calculate control levels of the reservoir.

4. Analyze and design gravity and earthen dam for various hydraulic conditions

5. Draw typical plans for various hydraulic structures.

The various steps involved in implementing the gamification technique are as given below.

\section{Formation of groups}

During the online teaching learning process by MS team or zoom it is very difficult to engage all 76 students from final year B. Tech. Civil Engineering class. The entire class was divided into two groups namely Control Group and Experimental Group for assessing their learning. The Control Group consisted of 26 students, while the Experimental Group consisted of 50 students. The 'Control Group' was assessed by 
using conventional techniques (question-answer, one minute paper etc.) whereas the Experimental Group' was assessed by adopting the Kahoot tool that involved mostly 'Multiple Choice Questions (MCQ)', and 'True-False' types questions.

2. Demonstration of online gamification tool :

In the initial stage the students of the entire class were oriented to the use of Kahoot tool for answering the questions using online mode. A separate session was conducted to demonstrate and train the students to use Kahoot using MS Teams virtual platform. The students were also adequately trained for other online gamification tools such as google docs, slido, mentimeter etc..

3. Preparation of Kahoot Quiz: Various sets of Kahoot Quizzes were prepared involving the MCQs, True-False questions etc. for assessment of students in the course 'IHS'. All quizzes prepared consisted of questions with the difficulty level of the questions generally appearing on the Graduate Aptitude Test in Engineering (GATE). The time limit of $60 \mathrm{sec}$ was set for answering each question. The quiz was conducted for 10 minutes at the end of the lecture.

\section{Preparation of Students:}

All the instructions were given to students before conducting the
'Kahoot Quiz' for assessment of students. The students' readiness was also confirmed before the actual conduct of the Kahoot Quiz.

5. Conducting the Kahoot Quiz during the lecture and Reporting

The Kahoot Quiz was launched at the end of every lecture using Microsoft team app. The Kahoot quiz code was informed to the 'Experimental Group' and students were asked to complete the quiz. The results of the quiz get displayed on the screen and the students can verify their answers and total score. The course teacher also gets the information about the students' understanding and the score obtained by them. The list of winning and runner up students is also displayed which motivates other students to actively participate in the quiz. The various steps involved in the implementation of the use of Kahoot Quiz are represented in the form of screenshots given below. (Fig.1 to Fig.3) 


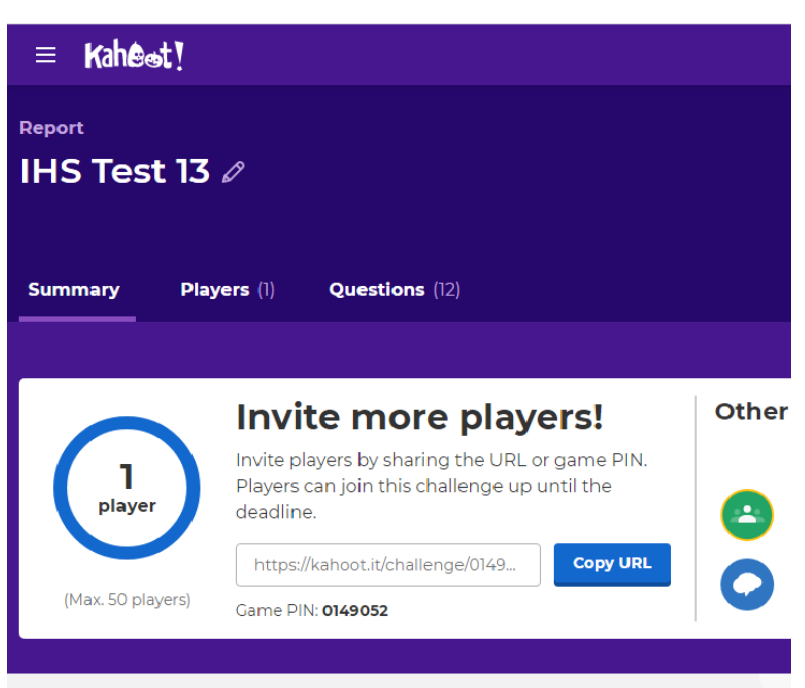

Fig. 1 Kahoot game Code

10.What type of canal alignment does the diagram repre

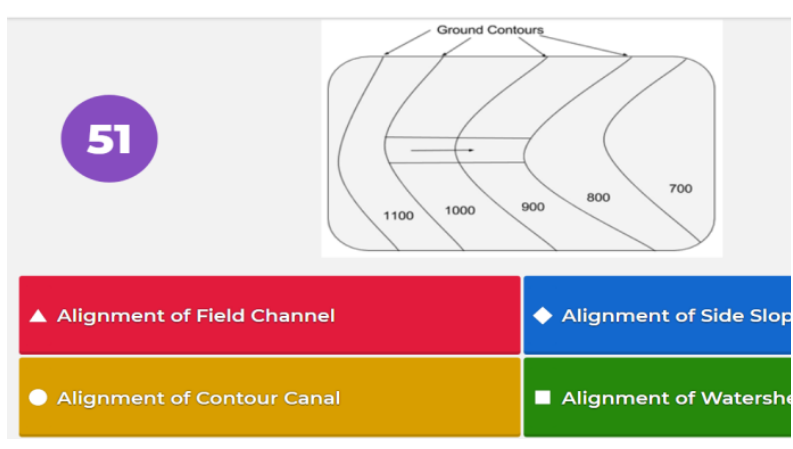

Q.11 Which type of alignment does the given figure repre

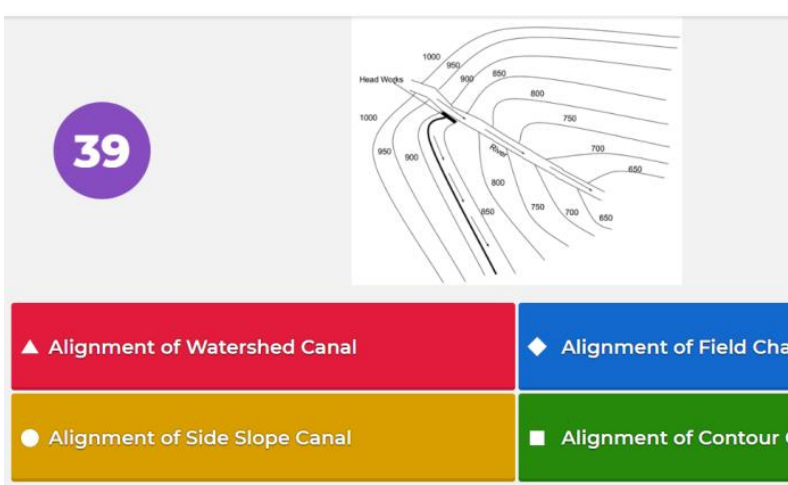

Fig. 2 Question and time allotment in quiz

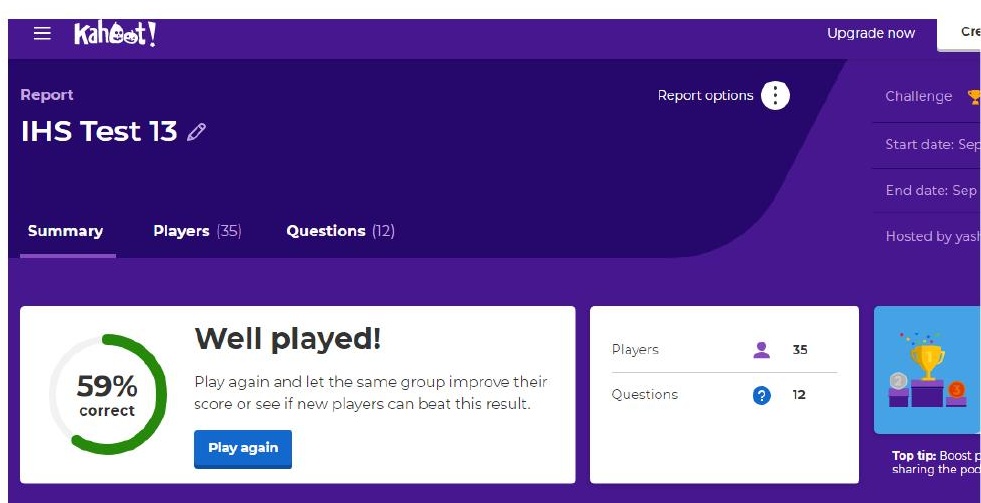

Fig.3 Podium for HIS Test 13

The course teacher of Irrigation and hydraulic Structures course also shared the name of winner and runner ups for each test. The IHS test 13 winners of the test were Roll No.1852005, 1702015 and 1502050. The runner ups for this test are Mr. Apurv and Roll no. 1602002. The sample test results of Kahoot Quiz was as shown in Fig.4

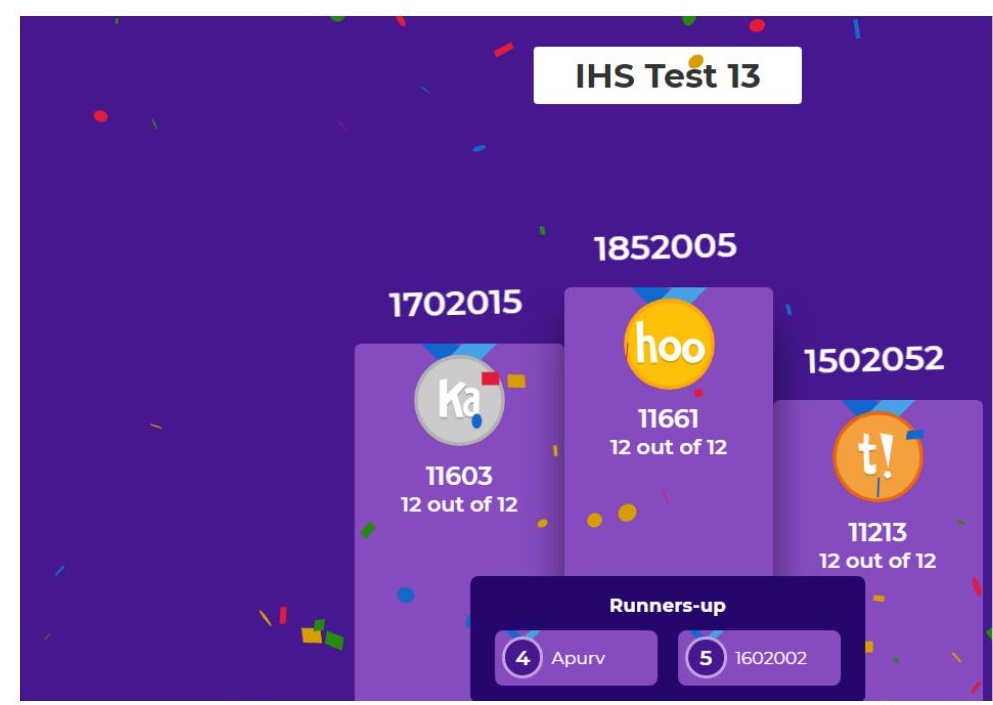

Fig.4 Irrigation and Hydraulic Structures

Test 13 winner and runner-ups

Fig. 5 showed detailed analysis of all 50

students with their final score. Out of 50 
students 35 students completed the quiz in time, 7 students needed help, 2 students didn't finish the test in a given time \& 6 students were not able to open the test due to low internet connection. From Fig. 5 It is concluded that $72 \%$ of students completed the quiz in time $14 \%$ need help for solving the quiz by using Kahoot. For each kahoot quiz course teacher evaluated all students from the experimental group.

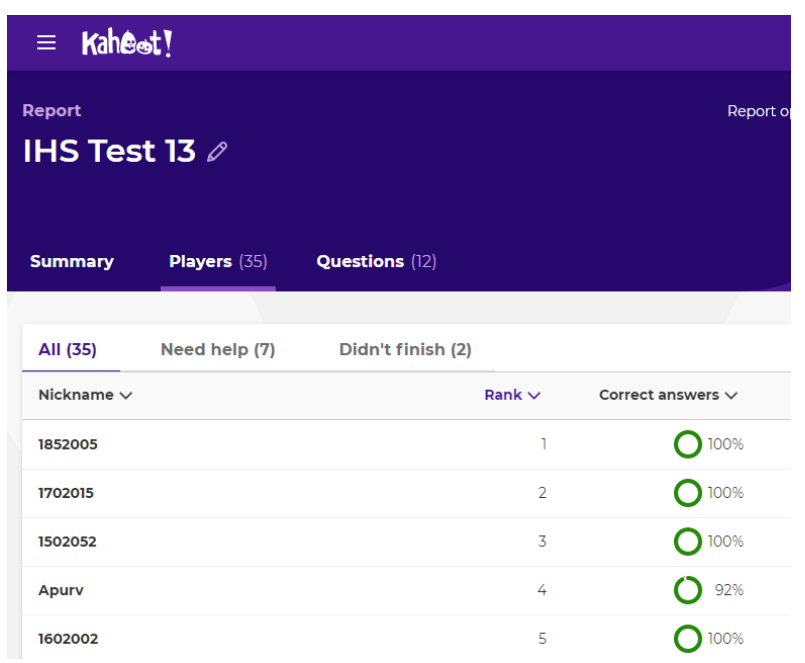

Fig.5 Detail analysis of 50 students in IHS test 13

\subsection{Result and discussion:}

The performance of students was observed in the Unit Test Examination by comparing the marks obtained by the students of both groups. The results giving the performance of the students in the Unit Test Examination are given in the figure below (Fig.6a \& 6b).

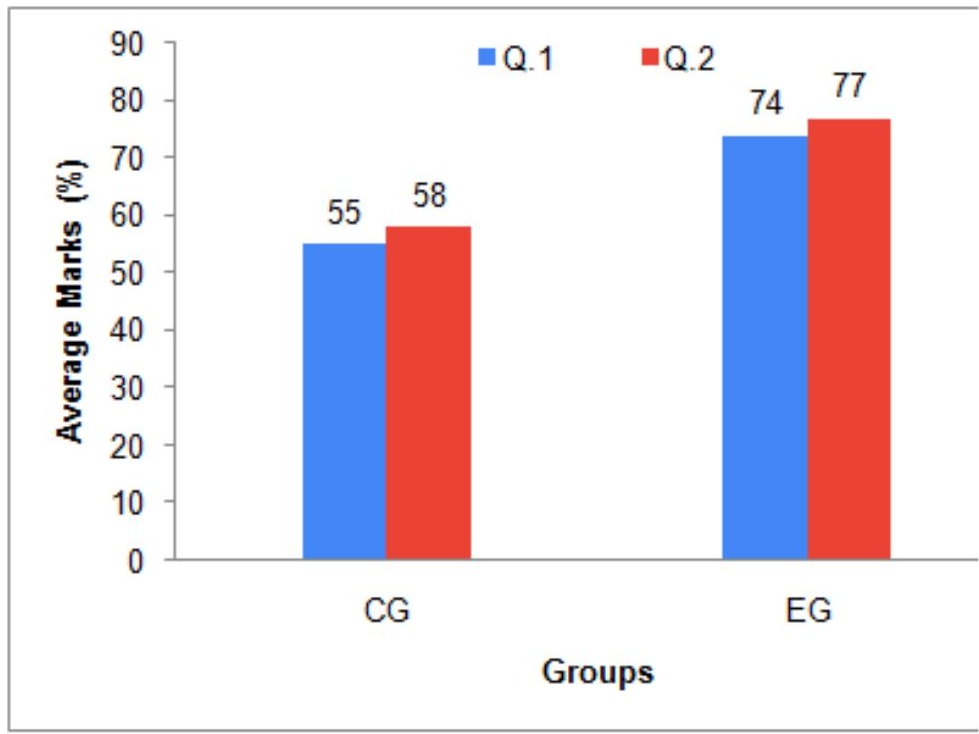

Fig.6 a: Avg. Marks of control and experimental group for Irrigation \& Hydraulic Structure course

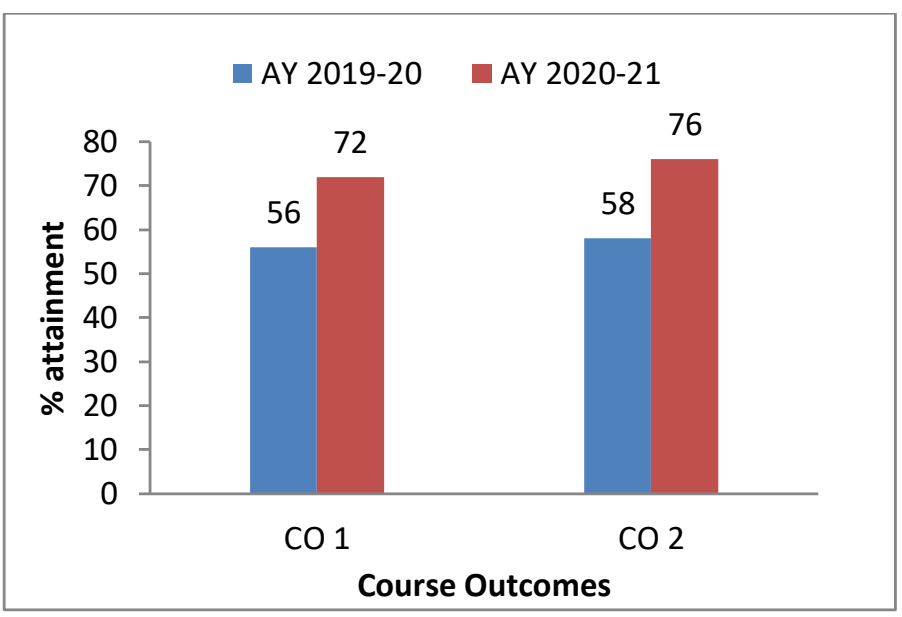

Fig.6 b: CO attainment for Irrigation and Hydraulic Structures Course

From fig. 6(a), it is observed that the performance of students' (i.e. average marks) for the 'Experimental Group' of students gets improved by over $18 \%$ as compared to the 'Control Group' of students. Thus, from the present study it is concluded that gamification active learning tool is very useful for assessment of learning levels of students and also 
engaging them during teaching learning process that leads to students quality learning. The comparison of attainment of the course outcomes by students assessed by using Kahoot tool (academic year 2020-21) and using conventional techniques (academic year 2019-20) is also indicated in the fig. 6(b). From fig.6(b), it is clearly observed that the attainment of expected course outcomes is substantially improved.

\section{Conclusions:}

From the study, following conclusions can be drawn:

1. Implementation of 'Kahoot tool' as an active learning tool results in the improvement of students' performance in the Unit Test examination by over $18 \%$ compared to the traditional teaching method and hence the improvement in the attainment of the course outcomes.

2. The use of Kahoot as a gamification tool helps in boosting the confidence level of students, as well as improvement in lifelong learning skills compared to the traditional method.

\subsection{Acknowledgement:}

Author would like to thank Dr. Mrs. S. S. Kulkarni, Director and Dr. S. K. Patil, Dean Academic, of K. E. Society's, Rajarambapu Institute of Technology, Rajaramnagar for motivating in carrying out the study. Author would also like to thank Dr. S. A. Thorat, OBE coordinator. The author appreciates the contribution of Final Year B. Tech. class students for their active role during implementation of gamification technique.

\subsection{References:}

1. Edel-Malizia S. (2015) Pedagogical Practices-Gallery Walk Retrieved [7.5.2019] from https://scholarsphere. psu.edu/downloads/1jw827964s.

2. Farrah, A.Z.(2015) doi: http://dx.doi.org/10.18326/rgt. v8i2.226-237.

3. Muhammad, H. R.(2016) Gallery Walk; An Alternative Learning Strategy in Increasing Students' Active Learning. Retrieved [7.5.2019] from http://repository.unhas.ac.id/ handle/123456789/18762.

4. Namaziandost E., Fariba R. E., Mehdi, N., and Rasool M.(2018) The Effect of Gallery Walk Technique on Pre-intermediate EFL Learners' Speaking Skill, Language Teaching Research Quarterly, (8), 1-15.

5. MichaelSailer Jan UlrichHense Sarah KatharinaMayr HeinzMandl (2017)How gamification motivates: An experimental study of the effects of specific game design elements on psychological need satisfaction, from Elsevier, Computer in human behavior, Vol69 (pg.371-380). 